6

cambridge.org/enc

\section{Research Paper}

Cite this article: Rebolo-Ifrán N, Graña Grilli M, and Lambertucci SA (2019). Drones as a Threat to Wildlife: YouTube Complements Science in Providing Evidence about Their Effect. Environmental Conservation 46: 205-210. doi: $10.1017 /$ S0376892919000080

Received: 17 October 2018

Revised: 11 April 2019

Accepted: 12 April 2019

First published online: 14 June 2019

\section{Keywords:}

drone; RPA; UAV; YouTube; wildlife disturbance

Author for correspondence:

Natalia Rebolo-Ifrán,

Email: nataliarebolo@comahue-conicet.gob.ar

\title{
Drones as a Threat to Wildlife: YouTube Complements Science in Providing Evidence about Their Effect
}

\section{Natalia Rebolo-Ifrán, Maricel Graña Grilli and Sergio A Lambertucci}

Grupo de Investigaciones en Biología de la Conservación, Laboratorio Ecotono, INIBIOMA (Universidad Nacional del Comahue - CONICET), Bariloche, Argentina (c) Foundation for Environmental Conservation 2019.

\section{CAMBRIDGE} UNIVERSITY PRESS

\section{Summary}

Although drones are becoming very common in the skies, most concerns about their use are not focused on their possible impact on wildlife. We used the information available from the scientific literature on the effects of drones on wildlife and complement it with Internet (YouTube) information to evaluate whether recreational activities using drones produce behavioural responses from wildlife. Scientific papers specifically evaluating the effects of drones on wildlife are scarce but increasing. Nonetheless, we found abundant videos in which many species from different taxonomic groups and multiple countries presented behavioural responses to drone overflights. Furthermore, $26 \%$ of the species that were disturbed are included in one of the International Union for Conservation of Nature categories of threat. We found that wildife that use aerial and terrestrial habitats are more likely to show a behavioural response than those occupying aquatic habitats. The Internet is becoming a source of evidence of disturbances to wildlife that should be considered, particularly for recreational activities. We advocate for the use of technology, but argue that funding and effort should be devoted to evaluating drone impacts on wildlife. We call for educational programmes for laypeople who use drones for recreation and for more research and regulations on their use in sensitive wildlife areas.

\section{Introduction}

Drones, unmanned aerial vehicles (UAVs) or remotely piloted aircrafts (RPAs) are relatively new components of human airspace use; however, they are increasingly used worldwide by laypeople and for ecological research (Anderson \& Gaston 2013, Christie et al. 2016, APO-100 FAA 2018, Canal \& Negro 2018). Currently, c. 2 million drones are sold each year worldwide, and figures are increasing significantly every year (APO-100 FAA 2018). The global drone market size is expected to be more than US $\$ 49$ billion by 2023 (Markets and Markets 2018). This implies that millions of drones are flying worldwide and most of them currently without any possibility of being controlled or without evaluation of their possible impacts on wildlife.

Drones are flown at low altitudes above ground level where most flying species live (Dolbeer 2006). However, there is little debate on their possible effects on wildlife (Hayes et al. 2014), and this has already generated calls for the study and minimization of drone disturbances to wildlife (Lambertucci et al. 2015, Hodgson \& Koh 2016, Mulero-Pázmány et al. 2017, Jiménez López \& Mulero-Pázmány 2019). Scientific literature on the subject is sparse, but it suggests that behavioural responses of wildlife to drones exist (Holldorf 2018). Moreover, there may be other unmeasured effects on the disturbed animals (e.g., physiological responses, fitness reduction), and uncertainty on how drones affect wildlife may limit their scientific use (Ditmer et al. 2015, Christie et al. 2016).

Scientific information is fundamental to estimating the possible effects of using drones on wildlife. However, in order to evaluate the possibility of drones impacting on wildlife worldwide, there is a need for a global evaluation on their use by laypeople. The Internet may be helpful in providing information on how people use drones when wildlife is present (Dylewski et al. 2017). Here, we used the information available from the scientific literature on the effects of drones on wildlife and information collected from the Internet (i.e., YouTube videos) regarding the interactions between wildlife and the drones used by laypeople all over the world. We then: (1) summarize the potential negative effects of drones on wildlife, classifying them by taxonomic group and geographical location; (2) assess whether habitat type (aerial, terrestrial and aquatic) results in differences in the behavioural response of wildlife to drone overflights; and (3) quantify the number of threatened species disturbed by drones found in YouTube data. We call for more research on drone impacts on wildlife and more regulations on drone use by laypeople in sensitive wildlife areas. 


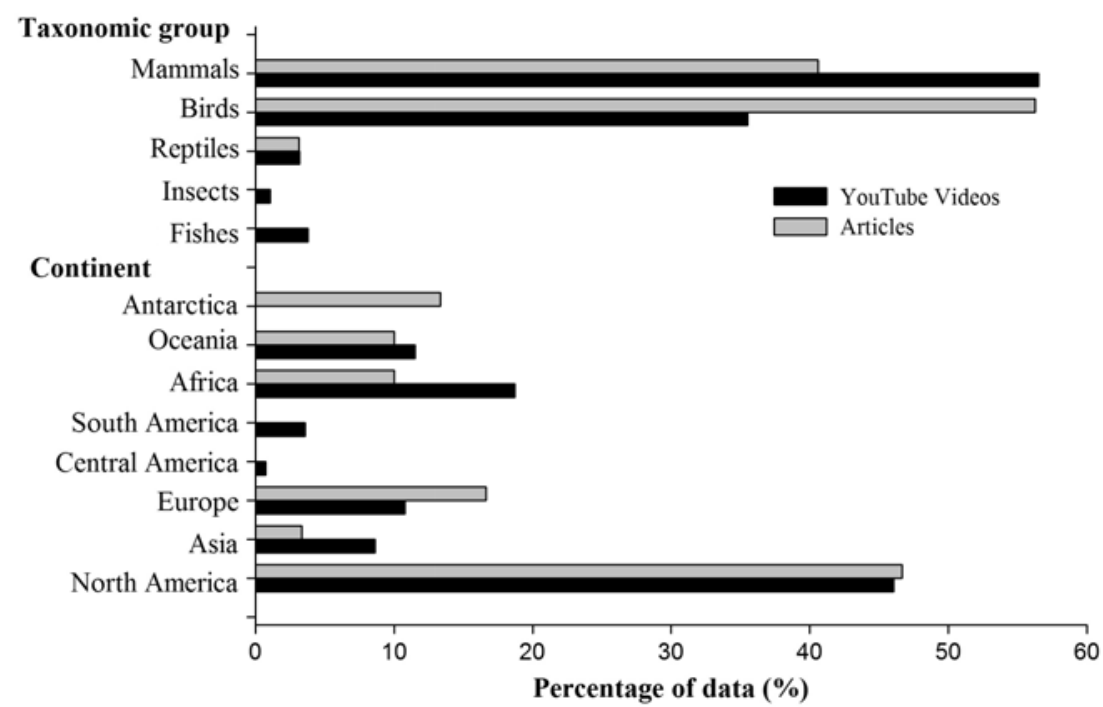

Fig. 1. Proportion of YouTube videos and scientific papers recording the disturbances from drones to wildlife separated by continent and taxonomic group.

\section{Material and Methods}

In order to evaluate the scientific knowledge on drone disturbances of wildlife, we performed a literature search on the topic through July 2018 inclusive. To perform the search, we used the following keywords: 'unmanned aerial vehicle', 'unmanned aircraft vehicle', 'unmanned aerial system', 'unmanned aircraft system', 'remotely piloted aircraft', 'drone', 'UAV', 'UAS', 'RPA' \& 'wildlife', 'animal behav*', 'aerial survey' \& 'disturb*', 'impact' on the Scopus database (www.scopus.com). We then complemented this information by searching the references of the papers found. We included every paper in which the behavioural responses of the animal studied due to the aerial vehicles were evaluated.

Additionally, we looked for any behavioural responses of wildlife to drones used by laypeople globally. For this, we searched for the terms 'drone', 'RPA' and 'UAV' combined each with 'wild animal', 'mammal', 'bird', 'reptile', 'fish', 'amphibian', 'frog', 'toad' and 'insect' on YouTube (www.youtube.com) up to July 2018. We then watched the first 200 videos of each YouTube search and, when possible, determined the species involved, the location and the behavioural response of each animal. When we could not identify the species or the location was not clear from the video description, we asked the owners of the videos for this information.

The type of drone (multi-rotor or fixed wing) can lead to different responses in the animals due to their flight characteristics, shape and/or acoustic pattern (McEvoy et al. 2016), so we noted the drone type in each of the videos analysed. In addition, as the habitat type could result in differences in the behavioural responses of animals (Ditmer et al. 2015), we evaluated whether the probability that wildlife showed a behavioural response to drones was influenced by the habitat predominantly used by the species (aerial, terrestrial or aquatic habitat). Drones can be considered as new occupants of airspace, and also of terrestrial habitats as they can fly at low altitudes. This could lead to an overlap with the wildlife that predominantly use these habitats. Aquatic animals have the advantage of being able to flee quickly by immersion, as drones cannot invade the aquatic habitat. Therefore, we defined the predominantly used habitat as the one used by each taxonomic group mainly for locomotion. We first classified the YouTube videos according to the presence or absence of a behavioural response to drones. Then, we used generalized linear models (GLMs) with binomial distributions (logit link) to test the habitat type as an explanatory variable of negative behavioural response, such as alert observation, escape, attack and collision. Although any type of behavioural response may mask a physiological response, in order to make a more conservative analysis, we excluded from the analysis those responses that did not necessarily involve a primarily early fear response, such as the curious approach.

Videos that clearly show an intention to provoke a behavioural response from wildlife may be not very useful for avoiding future unsafe flights for wildlife. In order to deal with this issue, we decided to categorize the types of interactions between the drones and wildlife into: (1) provoked, when the drone was directed quickly and in a straight line towards the animal; and (2) incidental, when the drone flew slowly and maintained distance between the animal or when the animal suddenly appeared in the place where the drone was flying. We then performed a new GLM analysis using only the videos with incidental interactions. Even though the videos that people upload to the Internet are likely to be biased towards those in which a behavioural response occurs in wildlife, our goal was not to weigh negative responses against nonresponses, but to evaluate what those negative responses are and whether they are related to wildlife habitat.

\section{Results}

The literature search resulted in 30 published articles in which the effects of drones on wildlife were recorded (including birds, mammals and reptiles; Fig. 1 and Table 1), and only 50\% were actually designed to detect those impacts. Studies were mainly conducted in North America, which represented $46.7 \%(n=14)$ of the total papers, followed by Europe $(16.7 \%, n=5)$. The rest of the studies were carried out in other continents, with a relevance that did not exceed $13.5 \%$ in any one case (Fig. 1). Twenty of these articles (66.7\%) found some behavioural effect on the species as a result of drone use. Most publications $(77.8 \%, \mathrm{n}=14)$ that evaluated the effects of drones on birds showed some behavioural change. Marine mammals showed some reaction to aerial vehicles in half of the studies $(n=4)$, while for terrestrial mammals, $40 \%$ of the studies $(n=2)$ presented some responses from the animals. The only study of reptiles found no behavioural responses. Because 
Table 1. Behavioural and other responses of wildlife to aerial vehicles found in scientific studies. We include the species studied, the altitude the drone was flown and wildlife responses to the presence of drones.

\begin{tabular}{|c|c|c|c|c|}
\hline Target & Altitude $(\mathrm{m})$ & Behavioural response & Other response & References \\
\hline \multicolumn{5}{|l|}{ Birds } \\
\hline Adélie penguin & $10-50$ & $\begin{array}{l}\text { Escape and intraspecific agonistic } \\
\text { behaviour }\end{array}$ & Not measured & Rümmler et al. (2016) \\
\hline $\begin{array}{l}\text { Tristan albatross, Atlantic yellow- } \\
\text { nosed albatross, sooty albatross, } \\
\text { Tristan skua }\end{array}$ & $20-150$ & Approach flights & Not measured & McClelland et al. (2016) \\
\hline Greater sage-grouse & $37-91$ & Stop display and crouch & Not measured & Hanson et al. (2014) \\
\hline Black-headed gull & $30-40$ & Flight & Not measured & Sardà-Palomera et al. (2012) \\
\hline Snow and Canada geese & 183 & No response & Not measured & Chabot and Bird (2012) \\
\hline Common tern & $91-122$ & $\begin{array}{l}\text { Upflights or fly away from the colony } \\
\text { followed by calls }\end{array}$ & Not measured & Chabot et al. (2015) \\
\hline Flamingo, mallard ducks & $4-30$ & Fly off & Not measured & Vas et al. (2015) \\
\hline Hooded crow & $6-25^{a}$ & $\begin{array}{l}\text { Adults: alarm calls, flights over of the } \\
\text { nest and dive-bomb the UAV; nestlings: } \\
\text { remain still and cower in the nest }\end{array}$ & Not measured & Weissensteiner et al. (2015) \\
\hline Waterfowl (63 species) & $40-120$ & Flight away from the UAV & Not measured & McEvoy et al. (2016) \\
\hline Adélie penguin & 350 & $\begin{array}{l}\text { Vigilance (look up and around) and a } \\
\text { slight increase in activity level }\end{array}$ & Not measured & Korczak-Abshire et al. (2016) \\
\hline Waterfowl (11 species) & $16-146$ & Flush behaviour & Not measured & Dulava et al. (2015) \\
\hline $\begin{array}{l}\text { Arctic cliff-nesting seabirds } \\
\text { (4 species) }\end{array}$ & $15-80$ & Alarm calls and flush behaviour & Reproductive output & Brisson-Curadeau et al. (2017) \\
\hline Lesser snow geese & $75-120$ & Head-cock and off-nest behaviours & Not measured & Barnas et al. (2018b) \\
\hline $\begin{array}{l}\text { Passerine, raptor species and ibis } \\
\text { ( } 3 \text { species) }\end{array}$ & $10-120$ & $\begin{array}{l}\text { Passerine: fly aggressively towards the } \\
\text { drone, nest out when approaching the } \\
\text { drones; ibis: flush from the nest }\end{array}$ & Not measured & Lyons et al. (2018) \\
\hline Shorebirds, waterfowl and seabirds & $20-122$ & Flush behaviour & Not measured & Drever et al. (2015) \\
\hline Penguins & $23-60$ & No response & Not measured & Goebel et al. (2015) \\
\hline Sub-Antarctic seabirds (11 species) & $3-50$ & $\begin{array}{l}\text { Vigilance, agonistic behaviour and } \\
\text { escape depending on the species and } \\
\text { the altitude of drone }\end{array}$ & Physiological & Weimerskirch et al. (2018) \\
\hline Peregrine falcon and silver gull & $40-80$ & No response & Not measured & Mclntosh et al. (2018) \\
\hline \multicolumn{5}{|l|}{ Marine mammals } \\
\hline Killer whale & $35-40$ & No response & Not measured & Durban et al. (2015) \\
\hline Bowhead whale & $120-210$ & No response & Not measured & Koski et al. (2015) \\
\hline Grey and harbour seals & $5-50$ & Move towards water & Not measured & Pomeroy et al. (2015) \\
\hline Ribbon and spotted seals & $90-200$ & Head up or fore-flippers extended & Not measured & Moreland et al. (2015) \\
\hline Leopard and fur seals & $23-60$ & No response & Not measured & Goebel et al. (2015) \\
\hline Grey seal & $75-80$ & No response & Not measured & Arona et al. (2018) \\
\hline Polar bear & $75-120$ & Head up & Not measured & Barnas et al. (2018a) \\
\hline Australian fur seal & $40-80$ & $\begin{array}{l}\text { From non-response to raise head and } \\
\text { move towards the ocean, depending } \\
\text { on drone model and flight height }\end{array}$ & Not measured & Mclntosh et al. (2018) \\
\hline \multicolumn{5}{|l|}{ Terrestrial mammals } \\
\hline Black bear & 20 & $\begin{array}{l}\text { Increased movement rates and } \\
\text { displacement distance away } \\
\text { from the area of UAV }\end{array}$ & Physiological & Ditmer et al. (2015) \\
\hline Elephant & $100-300$ & No response & Not measured & Vermeulen et al. (2013) \\
\hline Rhino & $10-260$ & No response & Not measured & Mulero-Pázmány et al. (2014) \\
\hline Elephant & 50 & Group and flee & Not measured & Hahn et al. (2017) \\
\hline Tibetan antelope & $150-200$ & No response & Not measured & Hu et al. (2018) \\
\hline \multicolumn{5}{|l|}{ Reptiles } \\
\hline Sea turtle & $20-30$ & No response & Not measured & Bevan et al. (2015) \\
\hline
\end{tabular}

${ }^{a}$ Height of the trees - the drone approached this height $\leq 5 \mathrm{~m}$ from the nest.

$\mathrm{UAV}=$ unmanned aerial vehicle.

two of the articles evaluated two taxonomic groups, the final number of samples for analysing behavioural responses from wildlife was 32 . The most frequent behavioural response was to escape (55.6\% of birds, $n=10 ; 40 \%$ of terrestrial mammals, $n=2$; and $25 \%$ of marine mammals, $\mathrm{n}=2)$. Species also responded to drones by attacking them $(11.1 \%$ of birds, $n=2)$, alert observation ( $25 \%$ of marine mammals, $\mathrm{n}=2$; and $11.1 \%$ of birds, $\mathrm{n}=2$ ) or curious approach (5.6\% of birds, $\mathrm{n}=1$ ). Complementarily to the assessment of behavioural response, only three articles evaluated another type of response, such as physiological and reproductive (Table 1).
The Internet search using YouTube resulted in a total of 184 (two with more than one taxonomic group, so the final number of samples was 186) videos of drones overflying wildlife in at least 33 countries, of which $61 \%$ showed some negative interaction between drones and wildlife, ranging from alert observations to escape or attacks on the drones (Table S1, available online). The videos include birds (35.5\%), marine mammals (34.9\%), terrestrial mammals $(21.5 \%)$, reptiles (3.2\%), fish $(3.8 \%)$ and insects (1.1\%). Those videos showed that from the 57 species (one correspond to a subspecies: Canis lupus dingo) we were able to identify, 
47 had some type of behavioural response to the aerial vehicles. Of these, $26 \%$ (12 species) are threatened and are included in one of the International Union for Conservation of Nature (IUCN) categories of threat (Table S1). The videos for which we could obtain location information $(\mathrm{n}=139)$ come mainly from North America $(46 \%, \mathrm{n}=64)$, but some are also from Africa $(18.7 \%, \mathrm{n}=26)$, Oceania $(11.5 \%, \mathrm{n}=16)$, Europe $(10.8 \%, \mathrm{n}=15)$, Asia $(8.6 \%, n=12)$, South America $(3.6 \%, n=5)$ and Central America $(0.7 \%, \mathrm{n}=1)$ (Fig. 1). Behavioural responses of wild and captive animals to the presence of drones were diverse. Birds $(n=66)$ responded with attack $(62.1 \%)$, escape $(19.7 \%)$, curious approach (9.1\%) and alert observation (1.5\%). Terrestrial mammals $(n=40)$ responded with escape $(45 \%)$, alert observation (25\%), attack (17.5\%) and curious approach (5\%). Marine mammals $(n=65)$ responded with escape $(16.9 \%)$ and alert observation $(1.5 \%)$. Reptiles $(n=6)$ responded with attack $(50 \%)$ and escape $(16.7 \%)$. Fish $(n=7)$ only responded with escape $(42.9 \%)$ and insects $(n=2)$ only with attack. Collisions with birds were also filmed $(6.1 \%)$. Non-responses were the remaining behaviours in each taxonomic group (Table S1).

The GLM showed that wildlife behavioural responses to aerial vehicles are influenced by the type of habitat predominantly used (Fig. 2 and Table S2). Wildlife using aerial habitats (birds and insects) and terrestrial habitats (terrestrial mammals and reptiles) have a greater probability of responding with a behavioural change to aerial vehicles (89.7\% confidence interval (CI): 65.7-97.7 and 84.7\% CI: $54.5-96.5$, respectively) than wildlife using aquatic habitats (marine mammals and fish, 20.8\% CI: 12.6-31.1; Fig. 2 and Table S2). We found the same results in the GLM when we only use the videos in which the interactions between wildlife and drones are incidental (Table S3).

\section{Discussion}

We found that many species ( 50$)$ from multiple countries from all continents and regions (marine and terrestrial species, from steppes to woodlands) are at least behaviourally disturbed by the presence of drones. Although scientific papers specifically evaluating the effects of drones on wildlife are scarce (e.g., Ditmer et al. 2015, Vas et al. 2015, Junda et al. 2016), we found that most videos of drones overflying wildlife caused a behavioural disturbance to animals. If we consider that we only examined those videos for which the titles matched the keywords of our search, they thus represent an underestimation of the actual number of wildlifedrone interactions, as many events are probably neither filmed nor published, especially those in which the animal may have been injured. Importantly, we cannot say that YouTube drone footage is indicative of the majority of drone flights, but just this small sample demonstrates that disturbances exist and that at least some people use drones in a way that disturbs animals. Moreover, we predict that this disturbance will increase in the near future considering the exponential increase in the use of drones (Hayes et al. 2014).

Most scientific or popular papers in this area deal with the benefits of using drones to improve the research, communication and recreational activities (Anderson \& Gaston 2013, Christie et al. 2016). However, these drones are already producing an impact on species. Historically, when people reached remote areas en masse by foot, bicycle, motorcycle or all-terrain vehicle, there was not much concern regarding the impacts on wildlife. However, those impacts were later found to be more serious than had been thought (Taylor \& Knight 2003, Knight \& Gutzwiller 2013). This could be the current case for drones. Drones may reach places that are very

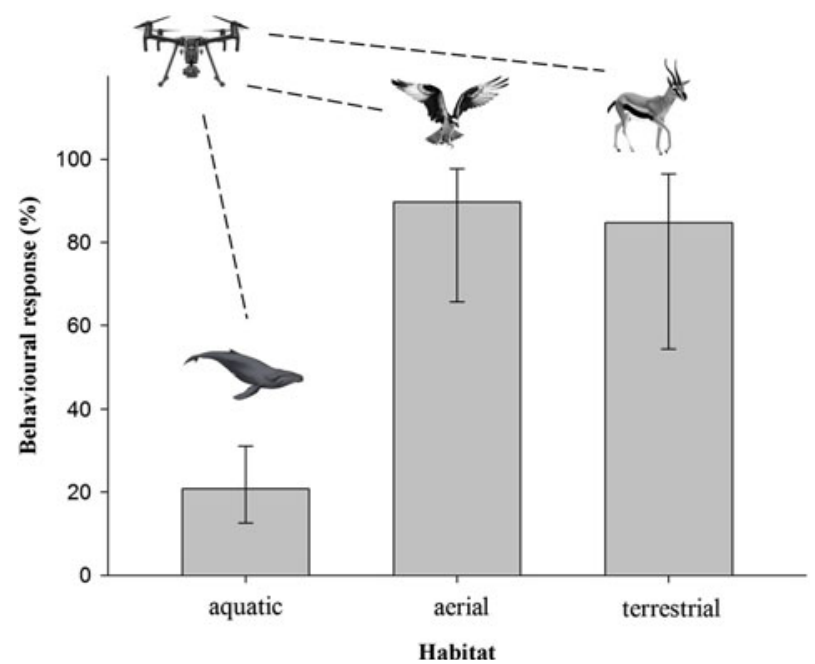

Fig. 2. Percentage of wildlife behavioural responses to aerial vehicles in relation to their main habitat.

inaccessible to humans (e.g., a nest on a high cliff or in a tree), disturbing remote areas that had experienced little human disturbances until now. In this sense, we found that a considerable percentage of endangered wildlife species reacts to drone overflights. It is important to highlight that the species that were not behaviourally disturbed in the videos could be affected when changing the way the drone is used (different flight heights, distances or other characteristics of the drone; see Vas et al. 2015, McEvoy et al. 2016, McIntosh et al. 2018, Weimerskirch et al. 2018). All drones used in the analysed YouTube videos were multi-rotor drones, so we could not make a comparison of the disturbances generated with the fixed-wing drones. This is not surprising given that multi-rotor drones are preferred for recreational use.

The wildlife most behaviourally affected by the drone disturbances were species that predominantly use airspace and terrestrial habitats. On the other hand, the least behaviourally disturbed species were those living underwater, such as dolphins and whales (Fig. 2). Differences in behavioural responses due to their habitat may be related to the perception of drones by wildlife. Birds may perceive aerial vehicles as potential competitors of airspace or as predators (McEvoy et al. 2016), which would explain their tendencies to attack and escape. In the case of terrestrial mammals, drones caused flush responses probably because such responses prevent an encounter with an unknown object. Animals living in the water, such as certain marine mammals, may be the least affected because acoustic and visual signals occur with less intensity underwater (Smith et al. 2016). However, despite the general lack of response from marine mammals, $35 \%$ of the recreational videos showed drone overflights of aquatic fauna. These behavioural differences due to habitat type may be masking other factors such as taxonomic group or species life history (e.g., territorial versus non-territorial species), which might explain how different species react to drones. While we do not have enough data to evaluate this, we advocate addressing these issues in future studies.

The only two scientific articles that evaluated both behavioural and physiological responses of wildlife to drones showed that the lack of instantaneous behavioural signals may be hiding other non-behavioural effects, such as physiological stress response (Ditmer et al. 2015, Weimerskirch et al. 2018). For that reason, it is necessary to control this type of recreational activity until more non-behavioural studies on these species are performed. We left 
out of the analysis behavioural changes in which wildlife showed a curious approach to the drone. This response was seen in birds and big cats, which seemed to show hunting behaviour towards the drone. Although in the first instance the approach to the drone does not seem to imply a negative response, the animals increase their energy expenditure in these activities without obtaining any reward (which could in turn lead to physiological changes). If these behaviours occur sporadically it may not represent a relevant impact, but if provoked many times or for long periods of time, it may be a relevant disturbance.

Only a very small proportion of the millions of drones are flown with scientific aims, and generally researchers are careful regarding the use of such surveying tools. Here, we found that the most common behavioural response of birds recorded in scientific articles was escape $(57.1 \%)$, while in videos it was attacking the aerial vehicle $(62.1 \%)$. Furthermore, while no scientific articles reported collisions of wild animals and drones, this was recorded in $6 \%$ of the videos. This could be due to laypeople perhaps flying the drone in order to generate an encounter with an animal, thus shortening the distance between them, which could lead to greater disturbance (Mulero-Pázmány et al. 2017). This suggests that recreational activities could be a greater source of impact to wildlife than scientific studies, which should be more cautions when approaching an animal.

Thus, it is important to highlight the differences of the possible effects of the scientific use of drones, which will rarely produce massive impacts, from those of the frequent and unregulated entertainment use of the general public. Nonetheless, every researcher should follow detailed protocols aimed at reducing any possible impacts of drones on the study species (Hodgson \& Koh 2016). Such protocols should minimize the negative impacts of these impressive tools. Moreover, studies should be designed in a species-specific way that allows the analysis of the possible impacts of using drones (Vas et al. 2015, Smith et al. 2016). All of the data on wildlife responses (behaviour, physiology, etc.) should be gathered in order to build information-based recommendations so as to assess the convenience of using drones for each particular species and site. Protocols should be clear enough to allow comparisons, and journals should request of authors that any research using drones as data gatherers must include information on the possible impacts.

In contrast to the myriad ethical considerations and codes of conduct that researchers must follow when studying wildlife, policies and programmes to avoid harassment of wildlife due to the recreational use of UAVs are largely absent - particularly on non-federal lands. The millions of drones that are sold each year and used worldwide by laypeople are producing conflicts with wildlife in the use of the airspace that merit special attention (Lambertucci et al. 2015, Mulero-Pázmány et al. 2017, APO-100 FAA 2018). Thus, recreational activities likely pose the most significant problem for many species, as the videos suggest. Moreover, the fact that many users upload videos with flashy titles alluding to attacks or collisions of wildlife with drones, particularly birds, suggests that these acts have become naturalized. This implies not only the lack of knowledge regarding the impacts of these actions, but also the incitement to watchers to continue to do likewise. Therefore, these impacts should be measured in order to produce evidence-based recommendations for the general public. Legislation and regulation on the use of drones should aim at reducing their disturbance to wildlife. Some advances in this matter have occurred, but mainly in protected areas (Sandbrook 2015). Educational programmes to advise people on the possible impacts that may be produced when using drones are needed. To this end, drones should be sold with disclosure information on this issue. Finally, the use of drones in sensitive areas should be avoided, always adopting the precautionary principle when no clear evidence on their possible impacts exists (Hodgson \& Koh 2016).

\section{Conclusion}

Robust scientific evidence is needed in order to apply management measures, build new infrastructure or use new technology. The utility of drones is undeniable. They provide access to remote areas, fine-scale resolution data and information at relatively low costs (Anderson \& Gaston 2013). They are also valuable tools for recreation, photography, sports, etc., and could play a revolutionary role in industrial fields (Giones \& Brem 2017). However, their users should carefully consider the secondary effects drones might have on wildlife, as they can exacerbate existing threats. We found that $26 \%$ of the species disturbed in the videos are at least considered 'Near Threatened' by IUCN, which implies that such a conflict exists and requires urgent regulation. Moreover, many species in the videos could not be identified, so the number of endangered species that are being exposed to these disturbances could be even greater. Some of our results are based on data provided by videos uploaded to YouTube, which could be biased towards showing wildlife responses to drones. Therefore, disturbances cannot be weighed over non-disturbances, but rather they make visible the problem of the unregulated use of drones for recreation. Although there is some concern regarding the impacts of drones on wildlife, scientific information is still not conclusive. However, the videos we found show that drones may disturb animals, and these constitute only a small subsample of a widespread phenomenon inflicted by people on wildlife. Thus, the Internet is becoming a source of evidence of disturbances to wildlife that should be considered. We advocate for the use of new technology, but first funding and effort should be devoted to evaluating its possible impacts.

Supplementary Material. For supplementary material accompanying this paper, visit www.cambridge.org/core/journals/environmental-conservation

Acknowledgements. We thank Karina Speziale and Sarah Young for their comments that helped to improve the manuscript, and 'Kini' Roesler for the help with identifying bird species from the videos.

Financial Support. The study was supported by the project PICT 0725/2014 and CONICET.

Conflict of Interest. None.

Ethical Standards. None.

\section{References}

Anderson K, Gaston KJ (2013) Lightweight unmanned aerial vehicles will revolutionize spatial ecology. Frontiers in Ecology and the Environment 11: $138-146$.

APO-100 FAA (2018) FAA aerospace forecast: fiscal years 2018-2038 [www document]. URL www.faa.gov/data_research/aviation/aerospace_forecasts/ media/FY2018-38_FAA_Aerospace_Forecast.pdf.

Arona L, Dale J, Heaslip SG, Hammill MO, Johnston DW (2018) Assessing the disturbance potential of small unoccupied aircraft systems (UAS) on gray seals (Halichoerus grypus) at breeding colonies in Nova Scotia, Canada. PeerJ 6: e4467.

Barnas AF, Felege CJ, Rockwell RF, Ellis-Felege SN (2018a) A pilot(less) study on the use of an unmanned aircraft system for studying polar bears (Ursus maritimus). Polar Biology 41: 1055-1062. 
Barnas AF, Newman R, Felege CJ, Corcoran MP, Hervey SD, Stechmann TJ, Rockwell RF, Ellis-Felege SN (2018b) Evaluating behavioral responses of nesting lesser snow geese to unmanned aircraft surveys. Ecology and Evolution 8: 1328-1338.

Bevan E, Wibbels T, Najera BMZ, Martinez MAC, Martinez LAS, Martinez FI, Cuevas JM, Anderson T, Bonka A, Hernandez MH, Pena LJ, Burchfield PM (2015) Unmanned aerial vehicles (UAVs) for monitoring sea turtles in near-shore waters. Marine Turtle Newsletter 145: 19-22.

Brisson-Curadeau É, Bird D, Burke C, Fifield DA, Pace P, Sherley RB, Elliott KH (2017) Seabird species vary in behavioural response to drone census. Scientific Reports 7: 17884.

Chabot D, Bird DM (2012) Evaluation of an off-the-shelf unmanned aircraft system for surveying flocks of geese. Waterbirds 35: 170-174.

Chabot D, Craik SR, Bird DM (2015) Population census of a large common tern colony with a small unmanned aircraft. PLOS ONE 10: e0122588.

Christie KS, Gilbert SL, Brown CL, Hatfield M, Hanson L (2016) Unmanned aircraft systems in wildlife research: current and future applications of a transformative technology. Frontiers in Ecology and the Environment 14: 241-251.

Canal D, Negro JJ (2018) Use of drones for research and conservation of birds of prey. In: Birds of Prey, pp. 325-337. Cham, Switzerland: Springer.

Ditmer MA, Vincent JB, Werden LK, Tanner JC, Laske TG, Iaizzo PA, Garshelis DL, Fieberg JR (2015) Bears show a physiological but limited behavioral response to unmanned aerial vehicles. Current Biology 25: 2278-2283.

Dolbeer RA (2006) Height distribution of birds recorded by collisions with civil aircraft. Journal of Wildlife Management 70: 1345-1350.

Drever MC, Chabot D, O'Hara PD, Thomas JD, Breault A, Millikin RL (2015) Evaluation of an unmanned rotorcraft to monitor wintering waterbirds and coastal habitats in British Columbia, Canada. Journal of Unmanned Vehicle Systems 3: 256-267.

Dulava S, Bean WT, Richmond OMW (2015) Environmental reviews and case studies: applications of unmanned aircraft systems (UAS) for waterbird surveys. Environmental Practice 17: 201-210.

Durban JW, Fearnbach H, Perryman WL, Leroi DJ (2015) Photogrammetry of killer whales using a small hexacopter launched at sea. Journal of Unmanned Vehicle Systems 3: 1-5.

Dylewski L, Mikula P, Tryjanowski P, Morelli F, Yosef R (2017). Social media and scientific research are complementary - YouTube and shrikes as a case study. The Science of Nature 104: 48.

Giones F, Brem A (2017) From toys to tools: the co-evolution of technological and entrepreneurial developments in the drone industry. Business Horizons 60: 875-884.

Goebel ME, Perryman WL, Hinke JT, Krause DJ, Hann NA, Gardner S, LeRoi DJ (2015) A small unmanned aerial system for estimating abundance and size of Antarctic predators. Polar Biology 38: 619-630.

Hahn N, Mwakatobe A, Konuche J, De Souza N, Keyyu J, Goss M, Chang'A A, Palminteri S, Dinerstein E, Olson D (2017) Unmanned aerial vehicles mitigate human-elephant conflict on the borders of Tanzanian Parks: a case study. Oryx 51: 513-516.

Hanson L, Holmquist-johnson CL, Cowardin ML (2014) Evaluation of the Raven sUAS to Detect and Monitor Greater Sage-Grouse Leks within the Middle Park Population. U.S. Geological Survey Open-File Report 2014-1205. Reston, VA, USA: US Geological Survey.

Hayes B, Jones C, Töpferm E (2014) Eurodrones Inc. Amsterdam, The Netherlands: Transnational Institute (TNI).

Hodgson JC, Koh LP (2016) Best practice for minimising unmanned aerial vehicle disturbance to wildlife in biological field research. Current Biology 26: R404-R405.

Holldorf E (2018). Avifauna Ethological Response to Unmanned Aircraft Systems [www document]. URL https://repository.usfca.edu/cgi/viewcontent.cgi? article $=1815 \&$ context $=$ capstone.

$\mathrm{Hu}$ J, Wu X, Dai M (2018) Estimating the population size of migrating Tibetan antelopes Pantholops hodgsonii with unmanned aerial vehicles. Oryx 1-9.

JiménezLópez J, Mulero-Pázmány M (2019) Drones for conservation in protected areas: present and future. Drones 3: 10.

Junda JH, Greene E, Zazelenchuk D, Bird DM (2016) Nest defense behaviour of four raptor species (osprey, bald eagle, ferruginous hawk and red-tailed hawk) to a novel aerial intruder - a small rotary-winged drone. Journal of Unmanned Vehicle Systems 4: 1-22.

Knight RL, Gutzwiller KJ, eds. (2013) Wildlife and Recreationists: Coexistence through Management and Research. Washington, DC, USA: Island Press.

Korczak-Abshire M, Kidawa A, Zmarz A, Storvold R, Karlsen SR, Rodzewicz M, Chwedorzewska K, Znój A (2016) Preliminary study on nesting Adélie penguins disturbance by unmanned aerial vehicles. CCAMLR Science 23: $1-16$.

Koski WR, Gamage G, Davis AR, Mathews T, LeBlanc B, Ferguson SH (2015) Evaluation of UAS for photographic re-identification of bowhead whales, Balaena mysticetus. Journal of Unmanned Vehicle Systems 3: 22-29.

Lambertucci SA, Shepard ELC, Wilson R (2015) Human-wildlife conflicts in a crowded airspace. Science 348: 502-504.

Lyons M, Brandis K, Callaghan C, McCann J, Mills C, Ryall S, Kingsford R (2018) Bird interactions with drones, from individuals to large colonies. Australian Field Ornithology 35: 51-56.

Markets and Markets (2018) Unmanned aerial vehicle (UAV) drones market worth 48.88 billion USD by 2023 [www document]. URL www. marketsandmarkets.com/PressReleases/commercial-drones.asp.

McClelland GTW, Bond AL, Sardana A, Glass T (2016) Rapid population estimate of a surface-nesting seabird on a remote island using a low-cost unmanned aerial vehicle. Marine Ornitholog 44: 215-220.

McEvoy JF, Hall GP, McDonald PG (2016) Evaluation of unmanned aerial vehicle shape, flight path and camera type for waterfowl surveys: disturbance effects and species recognition. PeerJ 4: e1831.

McIntosh RR, Holmberg R, Dann P (2018) Looking without landing - using remote piloted aircraft to monitor fur seal populations without disturbance. Frontiers in Marine Science 5: 202.

Moreland EE, Cameron MF, Angliss RP, Boveng PL (2015) Evaluation of a ship-based unoccupied aircraft system (UAS) for surveys of spotted and ribbon seals in the Bering Sea pack ice. Journal of Unmanned Vehicle Systems 3: 114-122.

Mulero-Pázmány M, Jenni-Eiermann S, Strebel N, Sattler T, Negro JJ, Tablado $\mathrm{Z}$ (2017) Unmanned aircraft systems as a new source of disturbance for wildlife: a systematic review. PLoS ONE 12: e0178448.

Mulero-Pázmány M, Stolper R, Van Essen LD, Negro JJ, Sassen T (2014) Remotely piloted aircraft systems as a rhinoceros anti-poaching tool in Africa. PLoS ONE 9: e83873.

Pomeroy P, O'Connor L, Davies P (2015) Assessing use of and reaction to unmanned aerial systems in gray and harbor seals during breeding and molt in the UK. Journal of Unmanned Vehicle Systems 3: 102-113.

Rümmler MC, Mustafa O, Maercker J, Peter HU, Esefeld J (2016) Measuring the influence of unmanned aerial vehicles on Adélie penguins. Polar Biology 39: 1329-1334.

Sandbrook C (2015) The social implications of using drones for biodiversity conservation. Ambio 44: 636-647.

Sardà-Palomera F, Bota G, Viñolo C, Pallarés O, Sazatornil V, Brotons L, Gomáriz S, Sardà F (2012) Fine-scale bird monitoring from light unmanned aircraft systems. IBIS 154: 177-183.

Smith CE, Sykora-Bodie ST, Bloodworth B, Pack SM, Spradlin TR, LeBoeuf NR (2016) Assessment of known impacts of unmanned aerial systems (UAS) on marine mammals: data gaps and recommendations for researchers in the United States. Journal of Unmanned Vehicle Systems 4: 31-44.

Taylor AR, Knight RL (2003) Wildlife responses to recreation and associated visitor perceptions. Ecological Applications 13: 951-963.

Vas E, Lescroël A, Duriez O, Boguszewski G, Grémillet D (2015) Approaching birds with drones: first experiments and ethical guidelines. Biology Letters 11: 20140754.

Vermeulen C, Lejeune P, Lisein J, Sawadogo P, Bouché P (2013) Unmanned aerial survey of elephants. PLoS ONE 8: e54700.

Weimerskirch H, Prudor A, Schull Q (2018) Flights of drones over sub-Antarctic seabirds show species- and status-specific behavioural and physiological responses. Polar Biology 41: 259-266.

Weissensteiner MH, Poelstra JW, Wolf JBW (2015) Low-budget ready-to-fly unmanned aerial vehicles: an effective tool for evaluating the nesting status of canopy-breeding bird species. Journal of Avian Biology 46: 425-430. 